\title{
Effectiveness of different regimens of a collective topical treatment using a solution of copper and zinc chelates in the cure of digital dermatitis in dairy farms under field conditions
}

\author{
A. Relun, ${ }^{\star} \dagger \ddagger \S{ }^{1}$ A. Lehebel, $\S$ N. Bareille, ${ }^{\star} \ddagger \S$ and R. Guatteo* $¥ \S$ \\ *UMT Cattle Herd Health Control, F-44307 Nantes, France \\ †French Livestock Institute, Department of Welfare, Health, Traceability and Hygiene, 149 rue de Bercy, F-75595 Paris, France \\ fLUNAM University, Oniris, Nantes-Atlantic National College of Veterinary Medicine, Food Science and Engineering, UMR 1300 Bio-Aggression, \\ Epidemiology and Risk Analysis, F-44307 Nantes, France \\ §INRA, UMR 1300 Bio-Aggression, Epidemiology and Risk Analysis, F-44307 Nantes, France
}

\begin{abstract}
A controlled field trial was conducted to evaluate in dairy cattle the benefit provided by different regimens of a collective topical treatment using a solution of copper and zinc chelates to cure digital dermatitis (DD) compared with individual treatment alone, and further to investigate factors that could explain variations in the clinical cure of DD lesions over 6 mo. The study was conducted between November 2009 and October 2010 and involved 4,677 dairy cows from 52 French dairy farms on which DD was endemic. The farms were quasi-randomly allocated to 1 of 4 treatment regimens for 6 mo: no collective treatment (control), walk-through footbath during 4 consecutive milkings every $4 \mathrm{wk}(\mathrm{FB} / 4 \mathrm{~W})$ or every $2 \mathrm{wk}(\mathrm{FB} / 2 \mathrm{~W})$ and collective spraying during 2 milkings every $2 \mathrm{wk}(\mathrm{CS} / 2 \mathrm{~W})$. For ethical and welfare reasons, all farmers also had to treat all detected active DD lesions with individual topical spraying of oxytetracycline. Digital dermatitis and leg hygiene were scored on all lactating cows during milking 7 times every 4 wk by 14 trained investigators. During these farm visits, data related to farm management were also collected. The curative effectiveness of collective treatments was assessed through a Cox survival frailty model as the probability of cure of an active DD lesion during at least 2 consecutive visits. The model was adjusted for farm and cow risk factors as well as initial DD prevalence. Monthly DD cure rates were $58,55,76$, and $76 \%$ in the control, $\mathrm{FB} / 4 \mathrm{~W}, \mathrm{FB} / 2 \mathrm{~W}$, and $\mathrm{CS} / 2 \mathrm{~W}$ regimens, respectively. The spontaneous monthly cure rate for untreated active DD lesions was $61 \%$. Hazard of cure of DD was increased by 1.28 and 1.41 when walk-through footbath and collective spraying, respectively, were applied over
\end{abstract}

Received September 27, 2011.

Accepted February 10, 2012.

${ }^{1}$ Corresponding author: anne.relun@oniris-nantes.fr
2 d every 2 wk compared with the control regimen. Applying a walk-through footbath 2 d every 4 wk was not sufficient to improve the cure of DD compared with individual treatments alone. Three main factors were identified as speeding DD healing: cleanliness of the feet, initial small size of the DD lesion, and additional individual topical treatment. Grazing tended to speed DD healing. These results highlight the need of combining several control measures, including individual and collective topical treatments, and improving foot hygiene and the early detection of DD lesions to ensure a high cure rate and rapid curing of digital dermatitis on endemically affected farms.

Key words: dairy cow, digital dermatitis, topical treatment, field trial

\section{INTRODUCTION}

Digital dermatitis (DD) is a widespread, contagious foot disease of dairy cows currently reported as endemic in almost all countries where cows are housed (Berry et al., 2004; Logue, 2011). It is manifested by circumscribed lesions on the skin of the foot, mostly between the heels of the hind foot (Read and Walker, 1998; Laven, 1999). Once introduced into a herd, mainly through the purchase of an infected cow, the infection may spread to the entire herd if the environment of the feet weakens the digital skin (Rodriguez-Lainz et al., 1996; Wells et al., 1999). Digital dermatitis is a serious issue for many dairy farmers as it can be very painful and cause lameness for their cows, thereby negatively affecting welfare and production (Losinger, 2006; Bruijnis et al., 2010; Green et al., 2010). Moreover, the prevalence of the disease has increased, affecting between 5 and $30 \%$ of cows in most affected herds (Somers et al., 2003; Holzhauer et al., 2006) with only anecdotal reports of eradication (Yeruham and Perl, 1998).

Whereas collective topical treatments have been used widely to control DD, particularly in large herds and in herds with a high proportion of affected cows, none 
meet all of the following requirements: safe for the user, cow, and environment; proven effectiveness in controlling DD over the long-term; and easy to implement on farms with different housing systems.

Walk-through footbaths containing antibiotics, formalin, or copper sulfate have been reported to successfully control digital dermatitis in clinical trials and anecdotal reports (Laven and Proven, 2000; Laven and Hunt, 2002a). Nevertheless these products have been abandoned progressively in European countries and are no longer recommended in footbaths for several reasons: antibiotics are not licensed for footbath use in the European Union, antibiotic resistance may develop (Shearer and Hernandez, 2000), formalin is carcinogenic (IARC, 2004), and the concentration of copper sulfate may reach a toxic threshold for plants and aquatic organisms when waste footbath solutions disposed into slurry are repeatedly spread over the soil (Stehouwer and Roth, 2004). Many alternative hoof-care products containing less toxic disinfectants have been developed over the past few years but science-based evidence regarding their effectiveness is scarce (Laven and Logue, 2006; Thomsen et al., 2008a; Speijers et al., 2010).

As walk-through footbaths are not always easy to implement in the field and some farmers are reluctant to use them (Auzanneau, 2009), a few alternative ways of applying collective treatments have been commercialised. However, again, few data are available on their effectiveness. Foam containing peracetic acid is available but field trial results showed inconsistent effectiveness in controlling DD (Journel and Carteron, 2001; Fiedler, 2004). Some hoof-care products are recommended not only for footbaths but also for collective spraying. However, to our knowledge, no investigation has tested the effectiveness of any of these products when applied through collective spraying to cure or prevent DD.

Finally, one of the major concerns when using a collective topical treatment to control DD is the lack of data on the best treatment strategy for a given farm regardless of the product used (Laven, 2003): it is not clear if collective topical treatments could be used to prevent $\mathrm{DD}$, cure $\mathrm{DD}$, or both, and consensus on the optimum frequency is lacking. For example, various frequencies for the application of copper sulfate have been tested, ranging from a daily application over 7 d (Laven and Hunt, 2002b) to 1 application every 2 wk (Speijers et al., 2010). Moreover, although several management practices are known to contribute to a higher risk of DD and may play a role in the cure of DD lesions (Rodriguez-Lainz et al., 1999; Somers et al., 2005; Holzhauer et al., 2006), clinical trials of hoof-care products rarely take management practices into account. These practices nevertheless may explain variations in effectiveness of similar treatment regimens assessed in different trials (Laven and Logue, 2006).

The purpose of our study was thus 2-fold: (1) to evaluate the potential benefit of using a collective treatment in addition to individual treatments in the cure of $\mathrm{DD}$, varying the manner and frequency of applying a solution of copper and zinc chelates, and (2) to identify management practices that may affect the clinical cure of DD lesions.

\section{MATERIALS AND METHODS}

The trial was designed to be a quasi-randomized, multi-arm, multi-site, controlled but not blinded, field trial. All procedures were carried out under the agreement of the Ethics Committee for Animal Experimentation of Pays de la Loire (CEEA, France). This trial is reported following the REFLECT and CONSORT recommendations (Moher et al., 2010; O'Connor et al., 2010).

\section{Animals and Management Practices}

The trial was conducted on 52 dairy farms located in Brittany and Pays-de-la-Loire, France, from November 2009 to October 2010. The number of farms included was determined by convenience criteria as the maximum number that could be followed, to implement the trial on farms with management practices as varied as possible. The farms were recruited through professional hoof-trimmers, veterinarians, and technicians from the animal health service and milk recording scheme. Farms had to meet the following requirements: (1) have experienced DD for over 2 yr (endemic situation) and (2) milk their cows in a milking parlor (location for DD scoring and DD treatments). As far as possible, farmers had to participate in the national milk recording scheme. Of the 52 farms included in the trial, one did not have any milk records. All cows in lactation during the trial were included in the study.

Most animals were housed in cubicles with solid concrete floors that were automatically or tractor scraped. On 2 farms, the floor was cleaned by manure flushing and 4 farms had slatted floors. The cows were housed in straw yards on 7 farms, mostly with solid concrete floors, that were scraped by tractor ( 5 farms); 1 farm had a dirt floor. On most farms, cows had access to pasture in the spring. However, some farms $(n=6)$ housed their cows indoors year round. The farmers included in the study milked, on average, 70 cows (range from 29 to 129 cows) twice daily. More than $80 \%$ of the cows were Prim'Holstein. Three farms had only Normande and 2 farms had half Prim'Holstein and half Normande breeds. On average, the 305-d cow milk 
production was $8,937 \mathrm{~kg}$ for Prim'Holstein cows (with a range of 5,357 to $12,636 \mathrm{~kg}$ ) and $6,457 \mathrm{~kg}$ for Normande cows (with a range of 3,369 to $9,513 \mathrm{~kg}$ ). The cows were trimmed preventatively on 33 farms by a professional hoof-trimmer or by their veterinarian. The cows were trimmed once a year on 19 farms and 2 or 3 times a year on 14 farms.

\section{Treatment Regimens and Hoof Care Products}

In the present trial, we chose to test regimens that included 2 methods (i.e., walk-in footbath or collective spraying) and 2 frequencies (i.e., $2 \mathrm{~d}$ every $2 \mathrm{wk}$ or every $4 \mathrm{wk}$ ) of applying a collective topical treatment. For ethical and welfare reasons, farmers were expected to additionally treat individually all active DD lesions that they detected with a specific protocol, regardless of the treatment regimen to which they had been assigned. During the first $4 \mathrm{wk}$, all the farmers applied only individual treatments to homogenize the initial treatment regimen between herds. The collective treatments were then applied over a 6 -mo period. In the control regimen, farmers did not apply any collective topical treatment (17 farms). In the footbath regimens, cows walked through a split footbath after 4 consecutive milkings every $4 \mathrm{wk}(\mathrm{FB} / 4 \mathrm{~W} ; 11$ farms) or every $2 \mathrm{wk}(\mathrm{FB} / 2 \mathrm{~W} ; 11$ farms). During the first 4 wk, subgroups were formed to assess the effectiveness of a more intensive initial treatment. Cows on half of the farms under each footbath regimen walked in the footbath every week after 6 consecutive milkings. The routine treatment of each regimen was then followed for the remaining 20 weeks. Cows that underwent an initial intensive treatment were in subgroups $\mathrm{FB} / 4 \mathrm{Wi}$ and $\mathrm{FB} / 2 \mathrm{Wi}$, whereas cows that did not were in subgroups $\mathrm{FB} / 4 \mathrm{Wni}$ and $\mathrm{FB} / 2 \mathrm{Wni}$. Under the collective spraying regimen, the front and back of the hind feet of all lactating cows were sprayed after 2 milkings $4 \mathrm{~d}$ apart every 2 wk (CS/2W; 13 farms). These regimens were scheduled in consultation with the product manufacturer.

The product used for collective topical treatments was chosen after evaluating a list of hoof care products available for collective topical treatment in France. The products had to meet the following criteria: be composed of disinfectant without copper sulfate or formalin, be reported to effectively control DD at least in reports of field trials, and be available for both walkthrough footbath and collective spraying. The product that fulfilled these criteria was one composed of copper and zinc chelates (Hoof-Fit, Intracare, Veghel, the Netherlands), with 2 presentations for collective treatment, one for use in walk-through footbaths (Hoof-Fit
Bath) and one for collective spraying (Hoof-Fit Liquid). With the recommended dilutions; namely, $5 \%$ for the footbath solution and $50 \%$ for the spraying solution, the dilutions of copper and zinc (chelated form) were 3.5 and $0.5 \mathrm{~g} / \mathrm{L}$, respectively, in the footbath solution, and $20 \mathrm{~g} / \mathrm{L}$ for both ingredients in the spraying solution. This product was previously reported to successfully control DD in a non-peer-reviewed field trial conducted on 4 Dutch farms when applied once a week in a split walk-through footbath combined with individual treatment of affected feet (Plomp, 2002).

To avoid having more than 150 cows pass through the footbath solution, it was changed after each milking if the farm milked more than 75 cows, and otherwise after every 2 milkings. The footbath used (Intra-Bath, Intracare) was a split walk-through footbath, consisting of 2 baths separated by a grill. Each bath measured $233 \mathrm{~cm}$ long $\times 32.5 \mathrm{~cm}$ wide $\times 19 \mathrm{~cm}$ high. The combined volume of the 2 baths was $160 \mathrm{~L}$. To prepare the footbath solution, farmers were provided a container to measure the solution before pouring it into the footbath where water was added to a depth of $12 \mathrm{~cm}$ (base of the central grill). In the collective spraying regimen, the product was sprayed through a 5 -L compression sprayer with a conical nozzle (Matabi, Agratech NW Ltd., Rossendale, UK). The farmers were provided a $50 \%$ diluted solution, so they just had to shake the drum of solution to mix before pouring it into the sprayer. For all collective treatments, before being treated, the hind feet were washed by the farmers with a medium water-hose when the cows entered the milking parlor.

The individual treatment consisted of topical spraying of oxytetracycline (oxytetracycline chlorhydrate, 30 $\mathrm{mg} / \mathrm{mL}$, Oxytetrin P, MSD Animal Health/Intervet, Beaucouzé, France) based on a standard protocol: 2 applications on water-cleaned feet $2 \mathrm{~d}$ apart, and 1 application consisting of 2 sprayings $15 \mathrm{~s}$ apart. This treatment could be repeated or the farmers could change the product if the lesion was still active $10 \mathrm{~d}$ after the first application.

Treatments were allocated quasi-randomly based on the proportion of hind feet detected with an active DD lesion; that is, with an erosive to ulcerative DD lesion during the prestudy visit. They were assigned by minimizing the imbalance between treatments for initial DD prevalence, with deviation from a random selection due to the implementation of footbaths being unfeasible on some farms and the unwillingness of some farmers to participate in any of the treatment regimens. The median proportion and range of hind feet with an active DD lesion at randomization and before implementation of collective treatments are described in Table 1. The main characteristics of cows at randomization are detailed in Table 2. 
Table 1. Median proportion of hind feet with an active digital dermatitis (DD) lesion (M1 or M2) per farm at randomization and $4 \mathrm{wk}$ later before implementation of collective treatments

\begin{tabular}{|c|c|c|c|c|c|}
\hline \multirow[b]{2}{*}{ Treatment $^{1}$} & \multirow{2}{*}{$\begin{array}{c}\text { Farms } \\
\text { (no.) }\end{array}$} & \multicolumn{2}{|c|}{ At randomization } & \multicolumn{2}{|c|}{$\begin{array}{l}\text { Before implementation } \\
\text { of collective treatments }\end{array}$} \\
\hline & & Cows (no.) & DD prevalence ${ }^{2}$ & Cows (no.) & DD prevalence ${ }^{2}$ \\
\hline Control & 17 & 1,028 & $0.09(0.03-0.37)$ & 1,034 & $0.06(0.02-0.16)$ \\
\hline $\mathrm{FB} / 4 \mathrm{~W}_{\mathrm{i}}$ & 5 & 408 & $0.12(0.07-0.23)$ & 405 & $0.13(0.05-0.22)$ \\
\hline $\mathrm{FB} / 4 \mathrm{~W}_{\mathrm{ni}}$ & 6 & 562 & $0.09(0.03-0.18)$ & 579 & $0.13(0.08-0.20)$ \\
\hline $\mathrm{FB} / 2 \mathrm{~W}_{\mathrm{i}}$ & 6 & 377 & $0.07(0.02-0.13)$ & 381 & $0.10(0.09-0.23)$ \\
\hline $\mathrm{FB} / 2 \mathrm{~W}_{\mathrm{ni}}$ & 5 & 394 & $0.07(0.00-0.18)$ & 400 & $0.08(0.03-0.28)$ \\
\hline $\mathrm{CS} / 2 \mathrm{~W}$ & 13 & 837 & $0.09(0.04-0.24)$ & 846 & $0.13(0.00-0.21)$ \\
\hline
\end{tabular}

${ }^{1}$ Control $=$ control regimen, no collective treatment; $\mathrm{FB} / 4 \mathrm{~W}$ and $\mathrm{FB} / 2 \mathrm{~W}=$ footbath applied after 4 consecutive milkings every $4 \mathrm{wk}(\mathrm{FB} / 4 \mathrm{~W})$ or every $2 \mathrm{wk}(\mathrm{FB} / 2 \mathrm{~W})$, without $\left(\mathrm{FB} / 4 \mathrm{~W}_{\mathrm{ni}}\right.$ and $\left.\mathrm{FB} / 2 \mathrm{~W}_{\mathrm{ni}}\right)$ or with an initial intensive treatment consisting of applying the footbath after 6 consecutive milkings every week during the first $4 \mathrm{wk}$ in 2 subgroups $\left(\mathrm{FB} / 4 \mathrm{~W}_{\mathrm{i}}\right.$ and $\left.\mathrm{FB} / 2 \mathrm{~W}_{\mathrm{i}}\right) ; \mathrm{CS} / 2 \mathrm{~W}=$ collective spraying on the hind feet applied after 2 milkings $4 \mathrm{~d}$ apart every $2 \mathrm{wk}$. The treatment solution for collective treatments was composed of copper and zinc chelates. All active DD lesions detected by the farmers were additionally treated individually with topical spraying of oxytetracycline.

${ }^{2}$ Proportion of hind feet with an active DD lesion (M1 + M2) per farm; median farm prevalence with range in parentheses.

\section{Follow-Up and Data Collection}

The farms were visited by 14 investigators, with each investigator monitoring between 1 and 11 farms.
The investigators were veterinarians ( 3 practitioners, 2 consultants, 2 final-year students, and the first author; 36 farms followed) or technicians specialized in health advising or hoof-trimming (6 technicians; 16 farms fol-

Table 2. Characteristics of cows at randomization

\begin{tabular}{|c|c|c|c|c|c|c|c|}
\hline Item & \multicolumn{6}{|c|}{ Treatment $^{1}$} & $\begin{array}{c}\text { All cows }{ }^{2} \\
(\mathrm{n}=3,606\end{array}$ \\
\hline \multicolumn{8}{|l|}{ Housing system } \\
\hline Cubicles & 756 & 364 & 562 & 377 & 352 & 837 & $3,248(90)$ \\
\hline Straw yards & 272 & 44 & 0 & 0 & 42 & 0 & $358(10)$ \\
\hline \multicolumn{8}{|l|}{ Grazing system } \\
\hline \multicolumn{8}{|l|}{ Herd size ${ }^{3}$} \\
\hline 29- 50 & 316 & 74 & 0 & 84 & 42 & 74 & $590(16)$ \\
\hline $51-80$ & 426 & 0 & 67 & 195 & 113 & 495 & $1,296(36)$ \\
\hline $81-129$ & 286 & 334 & 495 & 98 & 239 & 268 & $1,720(48)$ \\
\hline \multicolumn{8}{|l|}{ Breed } \\
\hline Prim'Holstein & 870 & 309 & 507 & 331 & 237 & 684 & $2,938(92)$ \\
\hline Normande & 24 & 59 & 0 & 0 & 95 & 0 & $178(6)$ \\
\hline$\geq 4$ & 188 & 79 & 89 & 51 & 88 & 156 & $651(20)$ \\
\hline \multicolumn{8}{|l|}{ Lactation stage } \\
\hline DIM $<90$ & 350 & 115 & 217 & 70 & 95 & 215 & $1,062(35)$ \\
\hline DIM 90-150 & 214 & 73 & 94 & 91 & 62 & 150 & $684(23)$ \\
\hline $\mathrm{DIM} \geq 150$ & 323 & 167 & 181 & 150 & 164 & 307 & $1,292(43)$ \\
\hline
\end{tabular}

${ }^{1} \mathrm{Control}=$ control regimen, no collective treatment; $\mathrm{FB} / 4 \mathrm{~W}$ and $\mathrm{FB} / 2 \mathrm{~W}=$ footbath applied after 4 consecutive milkings every $4 \mathrm{wk}(\mathrm{FB} / 4 \mathrm{~W})$ or every $2 \mathrm{wk}(\mathrm{FB} / 2 \mathrm{~W})$, without $\left(\mathrm{FB} / 4 \mathrm{~W}_{\mathrm{ni}}\right.$ and $\left.\mathrm{FB} / 2 \mathrm{~W}_{\mathrm{ni}}\right)$ or with an initial intensive treatment consisting of applying the footbath after 6 consecutive milkings every week during the first $4 \mathrm{wk}$ in 2 subgroups $\left(\mathrm{FB} / 4 \mathrm{~W}_{\mathrm{i}}\right.$ and $\left.\mathrm{FB} / 2 \mathrm{~W}_{\mathrm{i}}\right) ; \mathrm{CS} / 2 \mathrm{~W}=$ collective spraying on the hind feet applied after 2 milkings $4 \mathrm{~d}$ apart every $2 \mathrm{wk}$. The treatment solution for collective treatments was composed of copper and zinc chelates. All active DD lesions detected by the farmers were additionally treated individually with topical spraying of oxytetracycline.

${ }^{2}$ Number; \% of total in parentheses.

${ }^{3}$ Number of lactating cows. 
lowed). As investigators had varied experience in DD detection and scoring, they were trained by the first author to score DD and leg hygiene during a training session held before the study. This session took place in October 2009 on an experimental farm where DD was endemic. The investigators were first trained with a set of pictures and then on 32 lactating cows, with feet first being inspected in the milking parlor and then in a trimming chute. A second similar session was held halfway through the study (April 2010) to ensure the homogeneity of scorings: the investigators were asked to score the feet of 16 cows in the milking parlor for DD and leg hygiene without consulting each other. Scores were then compared and discussed and 16 new cows were scored. If an investigator's scorings were discordant from those of the other investigators during this session (i.e., if the mean kappa value of his/her scorings with those of other investigators was $<0.6$ ), data of the farms followed by that investigator were removed from the entire analysis. Throughout the trial, all investigators had 2 cards to which they could refer when necessary, one for DD and one for leg cleanliness scorings, with concise definitions of each possible score and their representative pictures. As investigators were in charge of explaining the study to the farmers and of checking whether the protocol was observed, they knew which treatment had been assigned to the farm they followed.

After the prestudy visit, each farm was visited 7 times, approximately 4 wk apart, with 1 visit just before the implementation of collective treatments and 6 follow-up visits. Each visit was based on 3 steps: (1) scoring of the hind feet of all lactating cows for DD and leg hygiene during milking, (2) checking any changes in management practices, and (3) checking compliance with the protocol.

Digital dermatitis status was assessed during milking using a telescopic mirror and a powerful headlamp as previously described by Relun et al. (2011). The hind feet of all lactating cows were washed using mediumpressure tap water before examination. Then, DD was scored using a 4-point nominal scale based on the one described by Döpfer et al. (1997) that reflects the different clinical stages of DD during the course of the disease (Figure 1). Stage M0 refers to normal skin, when no DD lesion is observed; M1 and M2 are active stages with erosive to ulcerative circumscribed lesions smaller (M1) or larger (M2) than $2 \mathrm{~cm}$ in diameter; and M4 is the chronic stage characterized by a dyskeratotic or proliferative lesion. In cases with more than one lesion on a hind foot, only the most severe one was recorded according to the proposed hierarchy of M2 > M1 > M4 Leg cleanliness was assessed by scoring the hind legs during milking using a 4-point nominal scale (Table 3 ) varying from clean (score 1) to very dirty (score 4), as described by Cook (2006) and Schreiner and Ruegg (2002).

Detailed information about housing characteristics and management practices was obtained using a questionnaire completed by the investigator and farmer together during the prestudy visit. Changes in these practices were checked during each visit. Dates of collective and individual treatments were recorded by the farmers throughout the study. Compliance with the protocol was checked by completing a questionnaire with the farmer during each visit. Data on health disorders, hoof care, movements of cows from the lactating
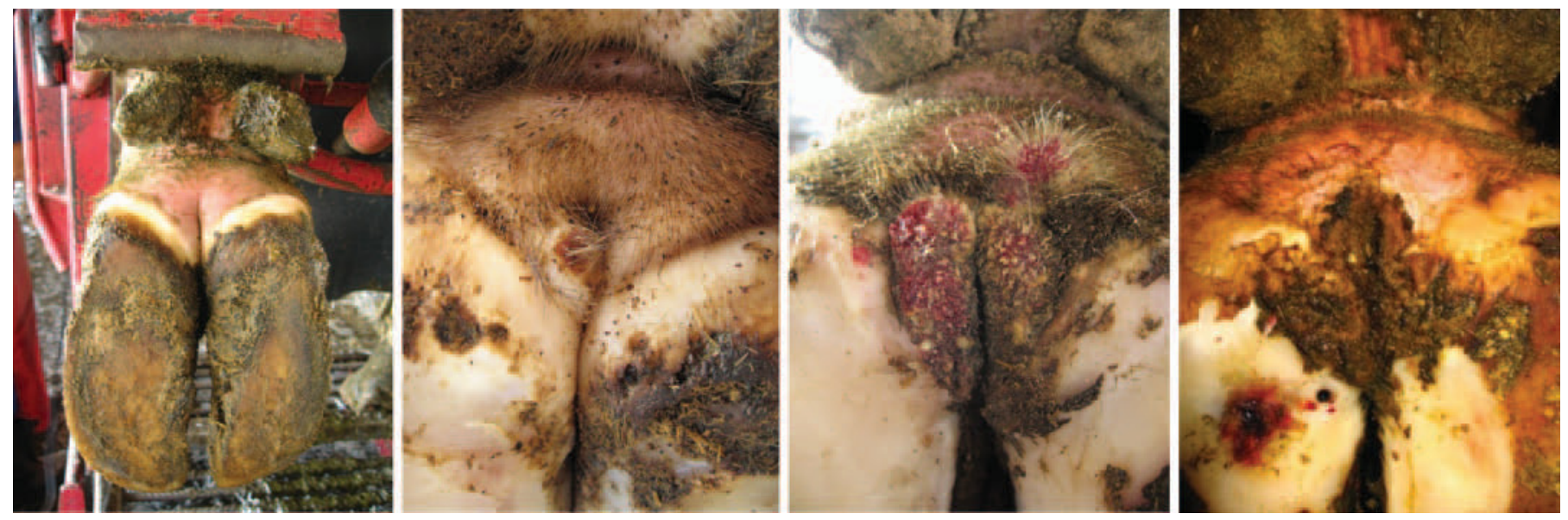

Figure 1. Illustration of the M stages used for scoring of digital dermatitis lesions (adapted from Döpfer et al., 1997). From left to right: M0 $=$ no circumscribed lesion; $\mathrm{M} 1=$ small circumscribed red to gray epithelial defects, less than $2 \mathrm{~cm}$ in diameter; M2 = classic ulcerative (bright red) or granulomatous (red-gray) stage with diameter $>2 \mathrm{~cm}$; M4 = late chronic stage characterized by a dyskeratotic lesion (mostly thickened epithelium), surface proliferation, or both. Color version available in the online PDF. 
Table 3. Scoring system for classification of leg hygiene adapted from Cook (2006) and Schreiner and Ruegg (2002)

\begin{tabular}{ll}
\hline $\begin{array}{l}\text { Leg hygiene } \\
\text { score }\end{array}$ & Description \\
\hline 1 & $\begin{array}{l}\text { Clean, little or no manure contamination of the lower limb } \\
\text { Slightly dirty, where the lower limb is lightly splashed with manure with less } \\
\text { than 50\% between dewclaws and shank covered by manure }\end{array}$ \\
3 & $\begin{array}{l}\text { Moderately dirty, with distinct plaques of manure on the foot, progressing up the limb } \\
\text { with more than } 50 \% \text { between dewclaws and shank covered by manure }\end{array}$ \\
4 & Very dirty, with confluent plaques of caked-on manure on the foot and higher up the lower limb \\
\hline
\end{tabular}

herd, and pasture management were also documented by the farmers, with a record of the identification number and the feet affected when necessary. These data were collected by the investigator on each visit. The farmers had to report any adverse effects observed to the corresponding author. Within $15 \mathrm{~d}$ after each visit, farmers were informed about the proportion of affected feet, but were not told which cows were affected so as to not interfere with their own detection of DD lesions. They had the option of withdrawing from the study at any time if the situation deteriorated. Data on breed, 305-d milk production, parity, and lactation stage were obtained from the milk recording scheme.

\section{Data Analysis}

All data were initially entered in a Microsoft Access database (Microsoft Corp., Redmond, WA). New variables were built from the raw data using SAS 9.1.3 (SAS Institute Inc., Cary, NC). Farm leg cleanliness was calculated at the farm level as the proportion of feet scored $\geq 3$ at each visit with 3 levels (good: $<25 \%$; fair: $25-50 \%$; poor: $>50 \%$ ) based on the levels defined by Cook (2006). Interventionism of the farmer for DD individual treatment was calculated at the farm level as the mean proportion of feet scored with an active DD lesion (M1 or M2) at each visit that had been treated individually by the farmer between this visit and the previous visit. This variable was used as a categorical variable with 3 levels (low: $\leq 10 \%$; medium: 11-50\%; high: $>50 \%$ ) based on the distribution of the variable.

The curative effectiveness of treatments was evaluated on the clinically cure of active DD lesions through survival analysis with a hind foot as the statistical unit. Survival analysis was carried out using the Survival Kit v6.0 (Ducrocq et al., 2010). For the purpose of analysis, an active DD lesion was defined as an early or acute DD stage (M1 or M2) on a hind foot. A foot was considered to be cured if an M0 or M4 lesion, considered nonactive, was observed during at least 2 consecutive visits, to ensure the healed status of the lesion. The outcome variable tested in the model was time to cure in days counting from the first date of observation of an active DD lesion. The cure date was determined as the first date without any active DD lesion. If the foot was not cured at the end of the follow-up period, the record was considered censored on this date. Recurrent lesions were not included in the analysis and feet observed fewer than 3 times or with consecutive visits spaced more than $45 \mathrm{~d}$ were removed from analysis. For survival analysis, we used a Cox proportional hazard model (Cox, 1972) that included a joined farm and investigator frailty effect to adjust for clustering within farms and investigators. All factors considered as potential effect modifiers of the cure rate were included as covariates in the Cox model (Table 4). Among them, a variable "individual treatment" was built to take into account that all active DD lesions were not necessarily treated with an individual treatment, as this treatment depended on farmers' detection of the lesions. The model was written as

$$
\lambda(t, X(t))=\lambda_{0}(t) \times \exp \left\{\sum_{i=1}^{p 1} \beta_{i} X_{i}+\sum_{j=1}^{p 2} \delta_{j} X_{j}(t)+U_{k l}\right\},
$$

where $\lambda(t, X(t))$ is the hazard function at time $\mathrm{t}$; that is, the probability for a foot of being cured at $t$, given that it is not cured before $t ; \lambda_{0}(t)$ is the unspecified hazard function; that is, the baseline hazard function, in the absence of covariates; $\beta_{i} X_{i}$ describes the effect of the $i$ th time-independent covariate; $\delta_{j} X_{j}(t)$ describes the effect of $j$ th covariate, which may vary over time; and $U_{k l}$ denotes the joined $k$ th farm and $l$ th investigator random effect, which is normally distributed. Six factors were included as time-varying predictors: leg cleanliness at the farm and cow levels, parity, stage of lactation, grazing at cow level, and individual application of a topical treatment. Leg cleanliness could change on each visit and other factors could change on any day of the follow-up. Individual topical treatment was considered to induce a notable cure from $10 \mathrm{~d}$ after the first application to $25 \mathrm{~d}$ after the last application, to take into account the time between effective cure and the observation of the cured status. This interval was selected among different intervals using the Akaike in- 
Table 4. Overview of farm-, cow-, and foot-related potential effect modifiers tested as covariates in the Cox frailty model

\begin{tabular}{|c|c|}
\hline Level & Factors \\
\hline Farm & $\begin{array}{l}\text { Digital dermatitis (DD) prevalence at first visit, grazing system, herd size, housing system, farm leg cleanliness, }{ }^{1,2} \\
\text { purchase of dairy cows, proportion of heifers, interventionism of farmer for DD individual treatment }{ }^{3}\end{array}$ \\
\hline Cow & Breed, parity, ${ }^{2}$ stage of lactation, ${ }^{2}$ grazing, ${ }^{2} 305$-d milk production,${ }^{4}$ leg hygiene score ${ }^{3}$ \\
\hline Foot & Initial stage of DD, individual topical treatment ${ }^{2}$ hoof-trimming, active DD lesion on contralateral foot \\
\hline
\end{tabular}

${ }^{1}$ Proportion of feet scored $\geq 3$ at each visit.

${ }^{2}$ Time-dependent covariates.

${ }^{3}$ Mean proportion of feet scored with an active DD lesion at a visit $n$ and treated individually by the farmer between visit $n$ and $n+1$.

${ }^{4}$ Adjusted for breed and parity.

formation criterion, which allows selection of the model that offers the best balance between goodness of fit and complexity (Akaike, 1974). An adjusted relative hazard ratio (HR) was estimated for each covariate from the hazard function by taking the exponent of the estimates of effects. This HR measures the instantaneous risk for a foot to become cured when exposed (e.g., to treatment regimen $\mathrm{FB} / 4 \mathrm{~W}$ ) versus being unexposed (e.g., control regimen).

The survival analysis was planned in 3 steps: in a first step, only subjects without missing data were included. If some variables did not contribute to the final model, a second analysis was performed that included subjects with missing data for these variables. If the subgroups of treatment regimens did not significantly differ (FB/4Wi vs. FB/4Wni, FB/2Wi vs. FB/4Wni), a third analysis was performed that considered only 4 treatment regimens: control, $\mathrm{FB} / 4 \mathrm{~W}, \mathrm{FB} / 2 \mathrm{~W}$, and $\mathrm{CS} / 2 \mathrm{~W}$. For each analysis, treatment regimens, all covariates, and biological relevant interactions first were tested in univariate analyses. These variables were selected for multivariate analysis if they contributed to the model at a $20 \%$ significance level (Dohoo et al., 2003). The variables were then selected in the multivariate model by backward stepwise selection, with treatment regimen forced into the model until all variables significantly $(P \leq 0.05)$ contributed to the model. During selection, all models were checked for confounding, which was assumed to occur when estimates changed by more than $20 \%$ when a variable was removed from the model. In such a case, the incriminated variable was forced into the model even if it did not significantly contribute to it. The proportional hazards assumption and the goodness-of-fit of the final model were checked by graphic procedures. The proportional hazards assumption was evaluated by plotting $\log -\log$ survival functions against time (Kalbfleisch and Prentice, 2002). Final model fit was assessed by evaluating the distribution of the CoxSnell residuals (Cox and Snell, 1966).

\section{RESULTS}

\section{Flow of Subjects}

The flow of subjects is described in Figure 2. Between December 21, 2009, and November 1, 2010, 4,677 cows $(9,354$ hind feet) were enrolled in the trial: $2,586,2,494$, 2,050 , and 2,224 in the control, FB/4W, FB/2W, and $\mathrm{CS} / 2 \mathrm{~W}$ regimens, respectively. In total, 81 cows from $\mathrm{FB} / 4 \mathrm{~W}$ did not complete the treatment as 4 farmers requested to stop treatment in the middle of the trial (due to a large increase in DD on their farms). These farms were followed until the end of the trial but data from their cows were truncated from analysis from the date of discontinuation. In total, 3,183 cows were scored for DD at least 3 times with fewer than $45 \mathrm{~d}$ between visits. Data from 193 cows were excluded from the analysis as they had been scored by one investigator whose DD scoring diverged from the others during the second meeting of investigators held midway through the trial. On the 4,588 hind feet that were available for analysis, 1,026 hind feet experienced, at least once, an active DD lesion and 634 had no missing data for variables constructed through milk records.

\section{Effect of Treatment Regimens and Management Factors on the Cure of $D D$}

In the first Cox analysis, no variable constructed through milk records (i.e., 305-d milk production, parity, lactation stage, and breed) was found to contribute significantly to the multivariate model at a $5 \%$ significance level. Among these variables, only parity was associated with faster cure rate in the univariate analysis at a $20 \%$ significance level with cows in third parity or greater having a 1.25 times higher hazard of cure compared with primiparous cows (95\% CI: 1.00-1.56).

Subjects without data from milk records were therefore included in a second analysis, wherein 1,027 hind feet from 515 cows milked on 45 farms were analyzed, with $296,42,210,60,137$, and 281 subjected to control, 
Hind feet enrolled $(n=9354)$

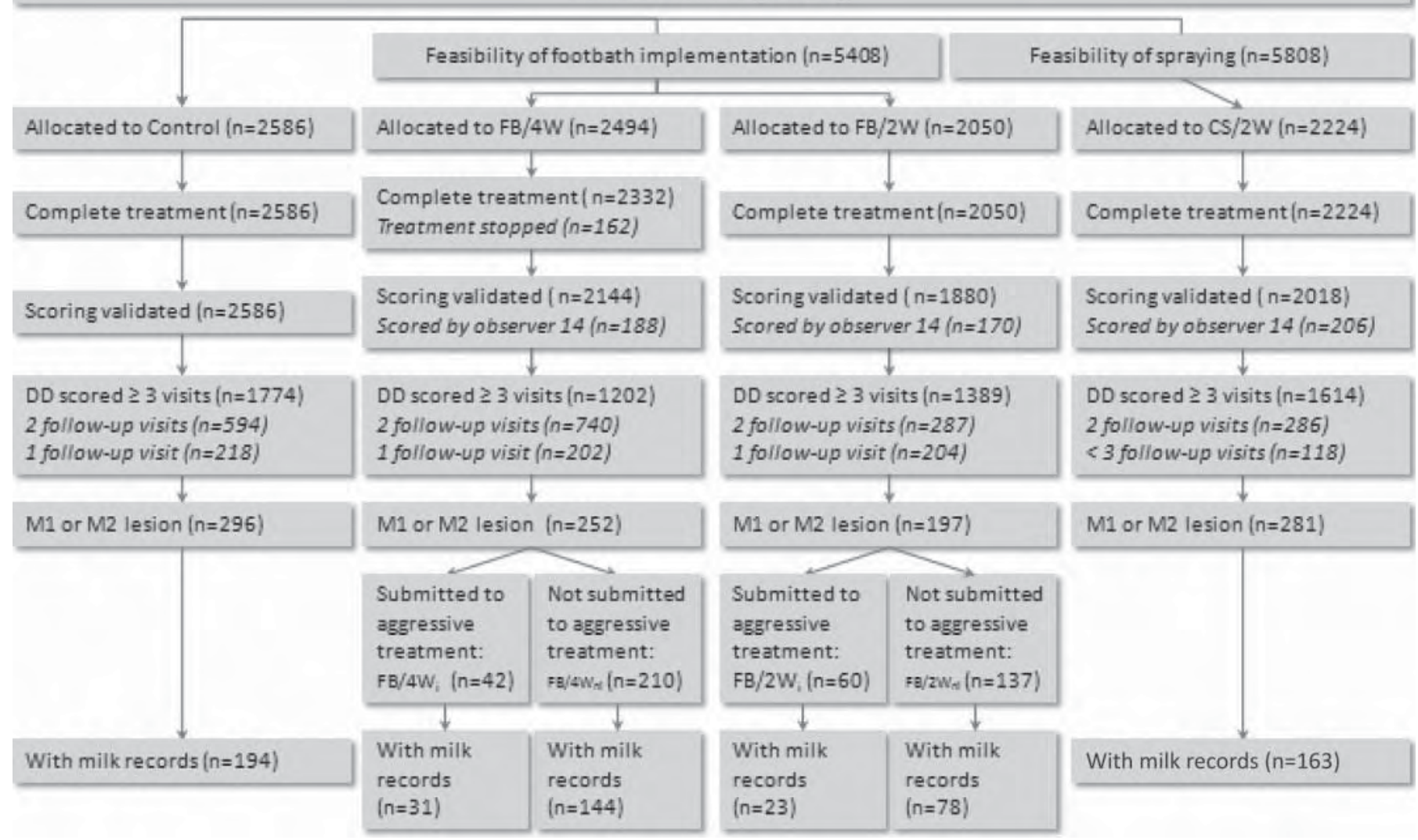

Figure 2. Diagram of subject flow. Control $=$ control regimen, no collective treatment; FB $/ 4 \mathrm{~W}$ and $\mathrm{FB} / 2 \mathrm{~W}=$ footbath applied after 4 consecutive milkings every $4 \mathrm{wk}(\mathrm{FB} / 4 \mathrm{~W})$ or every $2 \mathrm{wk}(\mathrm{FB} / 2 \mathrm{~W})$, without $(\mathrm{FB} / 4 \mathrm{Wni}$ and $\mathrm{FB} / 2 \mathrm{~W})$ or with an initial intensive treatment consisting of applying the footbath after 6 consecutive milkings every week during the first 4 wk in 2 subgroups $(\mathrm{FB} / 4 \mathrm{Wi}$ and $\mathrm{FB} / 2 \mathrm{Wi}) ; \mathrm{CS} / 2 \mathrm{~W}=$ collective spraying on the hind feet applied after 2 milkings $4 \mathrm{~d}$ apart every 2 wk. The treatment solution for collective treatments was composed of copper and zinc chelates. All active digital dermatitis (DD) lesions detected by the farmers were additionally treated individually with topical spraying of oxytetracycline. M1 and M2 lesions = active DD lesions smaller (M1) or larger (M2) than $2 \mathrm{~cm}$ in diameter.

FB/4Wi, FB/4Wni, FB/2Wi, FB/2Wni, and CS/2W, respectively. Cure of DD was achieved for $87 \%$ of affected feet during the trial, with a median time to DD cure of $28 \mathrm{~d}$, regardless of the treatment regimen. Spontaneous recovery occurred for $81 \%$ of nontreated feet (i.e., feet with an active DD lesion untreated in the control regimen), with monthly cure rates of 71 and $40 \%$ when lesions initially had been scored M1 and M2, respectively. Cure of DD was achieved for $84 \%$ of feet in the control regimen, $81 \%$ in $\mathrm{FB} / 4 \mathrm{Wi}, 79 \%$ in $\mathrm{FB} / 4 \mathrm{Wni}, 98 \%$ in $\mathrm{FB} / 2 \mathrm{Wi}, 93 \%$ in $\mathrm{FB} / 2 \mathrm{Wni}$, and $95 \%$ in CS $/ 2 \mathrm{~W}$. The monthly cure rate was $58 \%$ for control, $57 \%$ for $\mathrm{FB} / 4 \mathrm{Wi}, 55 \%$ for $\mathrm{FB} / 4 \mathrm{Wni}, 81 \%$ for $\mathrm{FB} / 2 \mathrm{Wi}$, $74 \%$ for $\mathrm{FB} / 2 \mathrm{Wni}$, and $76 \%$ for $\mathrm{CS} / 2 \mathrm{~W}$. Individual topical treatments were applied at least once on $25 \%$ (n $=163)$ and $33 \%(\mathrm{n}=125)$ of lesions scored initially as M1 and M2, respectively. Among individually treated feet, 89 and $83 \%$ initially scored M1 and M2 recovered during the trial, with monthly cure rate of 53 and $50 \%$, respectively. A higher proportion of lesions was treated individually in the control regimen $(36 \%, \mathrm{n}=107)$ and a lower proportion in the $\mathrm{CS} / 2 \mathrm{~W}$ regimen $(22 \%, \mathrm{n}=$ $61)$.

Because there were no significant differences in the Cox analysis between subgroups (FB/4Wi vs. FB/4Wni, $\mathrm{FB} / 2 \mathrm{Wi}$ vs. FB/2Wni), only results of the Cox analysis with the 4 treatment regimens are presented hereafter. Eight factors were associated with faster cure of active DD lesions at a 20\% significance level in the univariate analysis (Table 5): treatment every 2 wk with collective spraying or footbath, small herd size, improvement of leg cleanliness at farm level, grazing at cow level, additional individual topical treatment of DD, foot scored initially M1, and absence of DD on contralateral foot. After adjustment, 5 factors remained significantly associated with faster cure of $\mathrm{DD}$ : the $\mathrm{CS} / 2 \mathrm{~W}$ regimen, improvement of leg cleanliness at farm level, foot scored initially M1, additional individual topical treatment of $\mathrm{DD}$, and absence of active DD on contralateral foot (Table 5). The cumulative proportion of DD cure 
by treatment regimen is illustrated in Figure 3. The $\mathrm{CS} / 2 \mathrm{~W}$ and $\mathrm{FB} / 2 \mathrm{~W}$ regimens had, respectively, 1.41 (95\% CI: $1.02-1.94)$ and 1.28 (95\% CI: 0.91-1.80) higher DD cure hazard compared with the control regimen. Footbath applied every 4 wk was not associated with a higher DD cure hazard compared with the control regimen (HR: 0.96; 95\% CI: 0.68-1.37). The $\mathrm{CS} / 2 \mathrm{~W}$ regimen had 1.46 (95\% CI: 1.02-2.10) higher cure hazard compared with $\mathrm{FB} / 4 \mathrm{~W}$. The difference was not significant compared with FB/2W (HR: 1.10; $95 \%$ CI: 0.78-1.28). Among management factors, leg cleanliness at the farm level was associated with the highest DD cure hazard, with HR being higher than the most effective treatment regimen (Table 5).

\section{Adverse Effects}

On one farm where cows could lick the footbath when waiting for milking, 3 cows suffered severe depression and profuse diarrhea. These symptoms were likely linked to the absorption of hoof-care product, as feces were the same color as the hoof-care solution. All cows recovered within a few days after symptomatic treatment, and measures were carried out to avoid such incidents (improvement of blocking the access to footbath and addition of a repellent to the footbath solution).

\section{DISCUSSION}

The results of this study indicate that active DD lesions can effectively be clinically cured in endemically affected dairy herds by combining individual and collective topical treatments using a hoof-care product without copper sulfate or formalin with regimens that are acceptable under field conditions. Collective treatments using a solution of copper and zinc chelates associated with individual topical treatment were more effective than individual topical treatment alone when applied for $2 \mathrm{~d}$ every $2 \mathrm{wk}$ on cleaned feet through collective spraying in the milking parlor or when the cows walked for $2 \mathrm{~d}$ every $2 \mathrm{wk}$ through a split footbath. Treatments were not more effective when footbathing was applied for $2 \mathrm{~d}$ every $4 \mathrm{wk}$. The DD cure rate was improved markedly by 4 factors: good leg cleanliness at the farm level, DD lesion initially observed in an early stage, additional individual topical treatment of the DD lesion, and absence of active DD lesion on the contralateral foot.

In the present study, we developed an original approach for evaluating the effectiveness of treatments to cure DD. Rather than implementing treatments on a single farm, as has largely been done to date (Manske et al., 2002; Speijers et al., 2010; Teixeira et al., 2010), we chose to conduct the trial on a large number of com- mercial dairy farms endemically affected by DD. In this way, we could assess the effectiveness of treatments in different environments and estimate the relative effects of treatments and management practices on the cure of DD. We thus improved the extrapolation of results on the effectiveness of treatments on farms with different characteristics. The variety of environments was increased by the length of the follow-up period, which was long compared with that in previous studies. Treatments have often been assessed over a period of $10 \mathrm{wk}$ or less (Laven and Hunt, 2002b; Thomsen et al., 2008b; Speijers et al., 2010). In the current trial, the 6-mo follow-up period with an assessment of DD status every $4 \mathrm{wk}$ allowed us to assess effectiveness of treatments in different environments, such as housing or pasture, and to clarify the effect of risk factors on DD cure. The design of the study led us to use survival analysis to assess the curative effectiveness of treatments. In so doing, we could evaluate the effectiveness of treatments in terms of time needed to cure DD in addition to proportion of feet cured. Moreover, we could take into account the time-dependency of some risk factors, such as access to pasture or lactation stage, thus decreasing biased results. In return, we had to use a relatively simple tool to score DD, which had to be sufficiently reliable when used by different investigators and allow repeated scorings under conditions acceptable to farmers. We therefore used the DD scoring method previously described and validated by Relun et al. (2011), which consists of scoring the feet with a mirror and a headlamp in the milking parlor. We knew that by using this method we risked overestimating the proportion of cured feet because the interdigital space cannot be inspected and may still be infectious when the back of the foot appears to be cured (M4). We also knew that the use of this method would lead to DD scorings that were less accurate than those done in a trimming chute, and we thus risked underestimating the cure hazard ratios and the curative effectiveness of all tested factors, including collective treatments (Dohoo et al., 2003).

Previous studies have rarely found good effectiveness regarding cure of DD for collective topical treatments using hoof-care products without copper sulfate or formalin. Thomsen et al. (2008b) did not report any curative effectiveness of 3 hoof-care products containing glutaraldehyde, organic acids, or quaternary ammonium compounds. In that study, the treatments were applied using a split footbath with only one side of the cows treated for $2 \mathrm{~d}$ per week with 2 or $3 \mathrm{~d}$ between treatments over 8 wk. The lack of effectiveness could be because only one side was treated. Indeed, in the current study, we found that DD cure was slower when cows experienced DD on both hind feet. One explanation could be that cows affected on a single hind foot 
Table 5. Cox regression analysis to time to cure of active digital dermatitis (DD; M1 or M2) on hind feet

\begin{tabular}{|c|c|c|c|c|c|}
\hline \multirow[b]{2}{*}{ Item } & \multirow[b]{2}{*}{$\begin{array}{l}\text { Feet } \\
\text { (no.) }\end{array}$} & \multicolumn{2}{|c|}{ Univariate analysis } & \multicolumn{2}{|c|}{ Multivariate analysis } \\
\hline & & $\begin{array}{c}\text { Hazard ratio } \\
(95 \% \text { CI })\end{array}$ & $P$-value & $\begin{array}{c}\text { Hazard ratio } \\
(95 \% \mathrm{CI})\end{array}$ & $P$-value \\
\hline Control & 296 & Reference & & Reference & \\
\hline $\mathrm{FB} / 4 \mathrm{~W}$ & 252 & $0.88(0.62-1.26)$ & & $0.96(0.68-1.37)$ & \\
\hline $\mathrm{FB} / 2 \mathrm{~W}$ & 197 & $1.35(0.96-1.91$ & & $1.28(0.91-1.80)$ & \\
\hline $29-50$ & 158 & $1.37(0.98-1.91)$ & & - & \\
\hline $51-80$ & 429 & $1.12(0.84-1.49)$ & & - & \\
\hline 81-129 & 439 & Reference & & - & \\
\hline Farm leg cleanliness ${ }^{2,3}$ & & & 0.005 & & 0.02 \\
\hline Good & 570 & $1.54(1.12-2.10)$ & & $1.46(1.06-2.00)$ & \\
\hline Fair & 354 & $1.68(1.21-2.34)$ & & $1.56(1.12-2.18)$ & \\
\hline Poor & 102 & Reference & & Reference & \\
\hline Zero grazing & 85 & Reference & & - & \\
\hline Housing system & & & 0.43 & & - \\
\hline Straw yard & 99 & Reference & & - & \\
\hline Cubicles & 927 & $1.16(0.80-1.70)$ & & - & \\
\hline Initial farm DD prevalence & & & 0.86 & & - \\
\hline $\mathrm{M} 1+\mathrm{M} 2<0.10$ & 376 & $1.02(0.79-1.32)$ & & - & \\
\hline $\mathrm{M} 1+\mathrm{M} 2 \geq 0.10$ & 650 & Reference & & - & \\
\hline Interventionism of farmer ${ }^{4}$ & & & 0.27 & & - \\
\hline Low & 447 & Reference & & - & \\
\hline Medium & 415 & $1.05(0.81-1.37)$ & & - & \\
\hline High & 164 & $0.76(0.50-1.13)$ & & - & \\
\hline Proportion of calving heifers & & & 0.31 & & - \\
\hline 0 & 166 & $1.28(0.89-1.82)$ & & - & \\
\hline $0.01-0.10$ & 400 & $1.18(0.90-1.55)$ & & - & \\
\hline No & 738 & Reference & & Reference & \\
\hline DD initial stage & & & 0.002 & & 0.003 \\
\hline Early (M1) & 644 & $1.23(1.05-1.43)$ & & $1.26(1.08-1.47)$ & \\
\hline Acute (M2) & 383 & Reference & & Reference & \\
\hline Active DD on contralateral foot & & & 0.0002 & & 0.0002 \\
\hline Yes & 458 & Reference & & Reference & \\
\hline No & 569 & $1.32(1.14-1.53)$ & & $1.32(1.14-1.53)$ & \\
\hline Hoof-trimming & & & 0.33 & & - \\
\hline Yes & 44 & $0.86(0.62-1.53)$ & & - & \\
\hline No & 983 & Reference & - & - & \\
\hline
\end{tabular}

${ }^{1}$ Control $=$ control regimen, no collective treatment; FB $=$ footbath for 4 consecutive milkings every $4 \mathrm{wk}(\mathrm{FB} / 4 \mathrm{~W})$ or every $2 \mathrm{wk}(\mathrm{FB} / 2 \mathrm{~W})$; $\mathrm{CS} / 2 \mathrm{~W}=$ collective spraying on the hind feet for 2 milkings every $2 \mathrm{wk}$.

${ }^{2}$ Proportion of hind feet scored $\geq 3$ (good: $<25 \%$; fair: $25-49 \%$; poor: $\geq 50 \%$ ).

${ }^{3}$ Time-dependent covariates; number of feet at inclusion in the analysis.

${ }^{4}$ Mean proportion of hind feet with active DD lesion at each visit treated individually with oxytetracycline between this visit and next visit at herd level (low: <10\%; medium: 11-50\%; high: $>50 \%$ ).

${ }^{5}$ Oxytetracycline; 2 treatments $2 \mathrm{~d}$ apart on active lesion detected by the farmers.

can bear weight on the unaffected foot, thus decreasing contact of the affected foot with the soil and improving the cure rate. Speijers et al. (2010) tested a $2 \%$ hypo- chlorite footbath solution applied during 4 consecutive milkings on a weekly basis for 5 wk. They found no increase in curative effectiveness compared with the use 


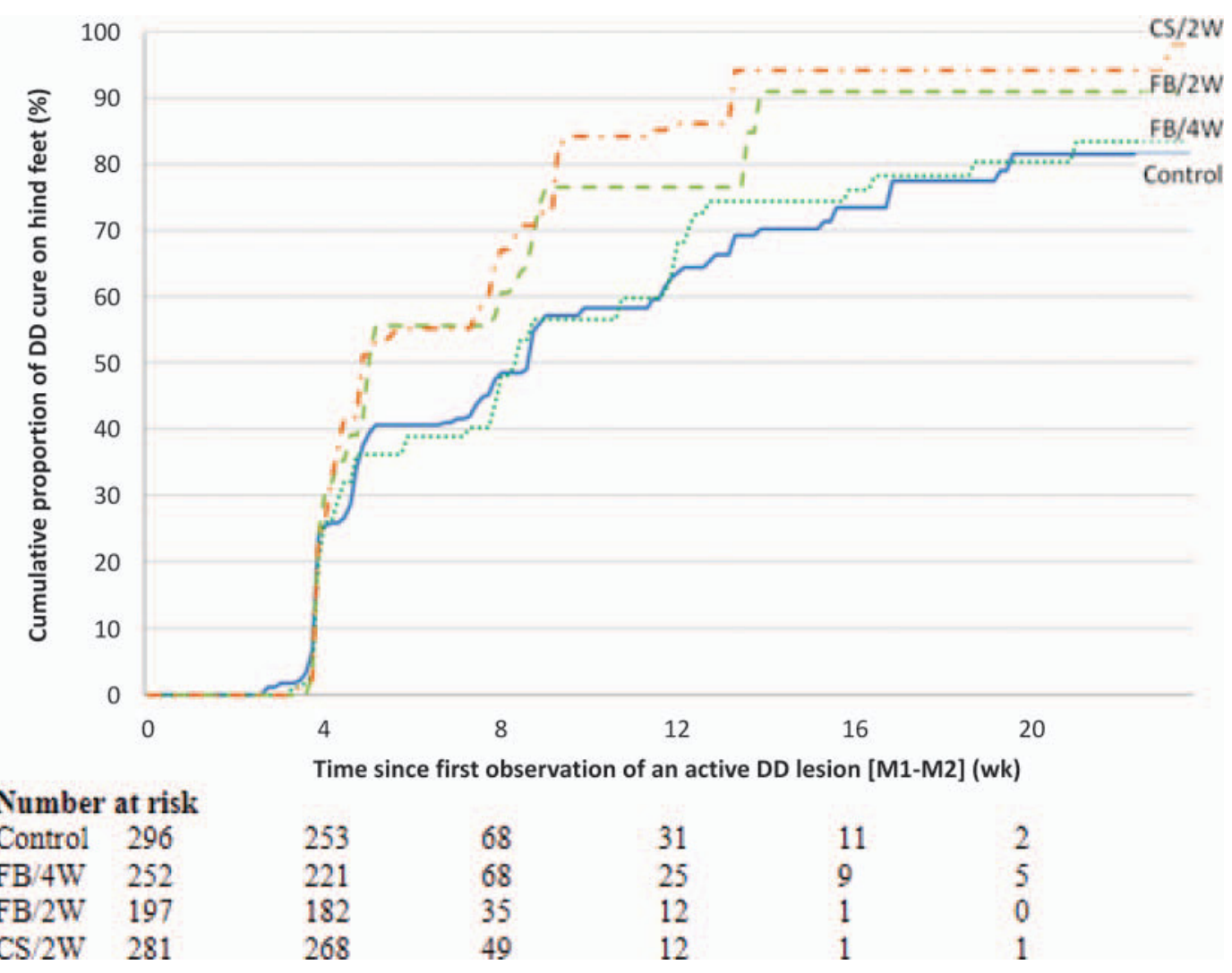

Figure 3. Cumulative proportion of cure on hind feet initially affected by active digital dermatitis (M1 or M2; see Figure 1) for each treatment regimen $($ control $=$ no collective treatment $($ control); FB $/ 4 \mathrm{~W}=$ footbath for 2 d every $4 \mathrm{wk} ; \mathrm{FB} / 2 \mathrm{~W}=$ footbath for $2 \mathrm{~d}$ every $2 \mathrm{wk}$; CS/2W $=$ collective spraying in the hind feet for $2 \mathrm{~d}$ every $2 \mathrm{wk}$ ). Color version available in the online PDF.

of water alone. Teixeira et al. (2010) found that a $5 \%$ phenoxyethanol footbath solution applied twice weekly for 4 wk had odds of curing DD similar to that of a $5 \%$ formalin solution or a $10 \%$ copper sulfate solution. However, the cure rates were low for all products (on average $22 \%$ feet cured with the phenoxyethanol footbath solution, $17 \%$ with formalin, and $24 \%$ with copper sulfate). To our knowledge, the only peer-reviewed study that found good results was that of Manske et al. (2002), which used acidified ionized copper footbath solution twice daily for a total of $47 \mathrm{~d}$ divided into 5 separate periods ranging in length from 3 to $16 \mathrm{~d}$ : $83 \%$ of affected feet were cured on the treated side within 5 mo.

In the present trial, copper and zinc chelate solution applied $2 \mathrm{~d}$ every $2 \mathrm{wk}$ on cleaned feet through collective spraying or through footbaths in addition to individual topical treatments demonstrated a higher and faster cure rate than individual topical treatments alone. The high proportion of cured feet in collective treatment regimens may be due to the cumulative effects of collective and individual treatments in addition to spontaneous recovery. Indeed, we observed a moderately high rate of spontaneous recovery without any treatment for M1 as well as M2 lesions. Recovery of an M1 lesion may be partly explained by this type of lesion sometimes occurring after an M2 lesion (Holzhauer et al., 2008; Döpfer, 2009) and, in such a case, it would be an M2 lesion in the process of healing. This may partly explain the higher cure rate observed for lesions initially scored as M1 compared with M2, as previously reported by Nishikawa and Taguchi (2008). Spontaneous recovery of M2 lesions was surprising. This phenomenon has previously been reported by Manske et al. (2002) and Vink (2006) and may occur when the feet are in a clean environment such as during the grazing period. Individual topical treatments were also effective in curing $\mathrm{DD}$, but the proportion of cured feet was lower than that found previously (Guterbock et al., 1995; Manske et al., 2002; Kofler et al., 2004). This could be because only the most severe DD lesions, and thus the hardest to cure, were detected and then treated individually by farmers. Nevertheless, only a small proportion of active DD lesions were detected and treated individually by the farmers. This lack of detection may explain the advantage of a strategy of collective treatments as 
they also cure the undetected lesions, particularly those that are small and thus not easy to detect but that recover the most quickly. However, we did not find any advantage of collective treatments when a footbath was only applied every $4 \mathrm{wk}$, which may be because the interval between 2 applications allowed the development of larger lesions, which are more difficult to cure. This may indicate that collective treatments using copper and zinc chelate solutions at the concentration used in this trial should be repeated at least every 2 wk to cure DD lesions better than individual treatments alone.

The frequency of application of collective treatments tested in this trial may seem low, as most trials evaluating hoof-care products applied them weekly or at least every 2 wk (Thomsen et al., 2008a; Speijers et al., 2010; Teixeira et al., 2010). However, we choose to test 2 frequencies, 4 consecutive milkings every $4 \mathrm{wk}$ and every 2 wk, because a recent survey (Auzanneau, 2009) revealed that many French farmers are reluctant to use a footbath and when they do, they tend to use it once a month or less because of the time needed to implement the treatments and the cost of the products. By testing 2 frequencies for footbath treatment, we demonstrated that applying a footbath on only $2 \mathrm{~d}$ every 4 wk was not effective to cure active DD lesions, even when a more intensive initial treatment was applied. However, the more intensive initial treatment was not found to be associated with a higher cure hazard, probably because only a few subjects were submitted to this intensive treatment. The particularly high cure rate in the $\mathrm{FB} / 2 \mathrm{Wi}$ subgroup suggested that increasing the frequency of treatment may quicken the healing of DD lesions.

One interesting finding was the effectiveness of collective spraying to cure DD lesions. To our knowledge, this application method had not been tested previously and it could be a good alternative to footbaths for collective treatment, particularly as the quantity of hoof-care product required is about 15 times less than that used in a footbath. The hoof-care solution was 5 times more concentrated when applied through collective spraying than through a footbath. This difference corresponds to the recommendations of the manufacturer, because the percentage of principal active compounds was quite different in both products.

Among factors tested as potential effect modifiers, leg cleanliness at the farm level was the one that most affected the cure of DD lesions, with HR equal to or greater than those found for effective treatment regimens. Although poor hygienic conditions in the foot environment are often implicated as potential risk factors for developing DD lesions (Rodriguez-Lainz et al., 1996; Laven, 1999; Wells et al., 1999), some authors have suggested that dirty conditions may impair the effectiveness of topical treatments. Kofler et al. (2004) advised keeping cows on a clean floor for 30 min after treatment to avoid dilution of the topical treatment with manure; Speijers et al. (2010) hypothesized that the lack of effectiveness of a $2 \%$ hypochlorite footbath solution could be due to dirty conditions. In the present trial, dirtiness may have affected the bioavailability of active compounds in DD lesions even though feet were precleaned with a water hose in the milking parlor and despite the fact that minerals were chelated, preventing them from being bound by organic matter. Dirtiness also may weaken the skin, thus delaying the healing of DD lesions. This finding highlights the need to provide a hygienic environment for feet to avoid infection but also to promote good healing of DD lesions. The next step would be to identify those management practices that improve foot cleanliness. A recent cross-sectional study (Nielsen et al., 2011) identified having access to pasture as an important factor in improving leg cleanliness, but they did not find any other management factors, including floor type and herd size, as significantly influencing leg cleanliness. Leg cleanliness might result from a combination of several interacting management practices, including type of housing, type of floor, frequency of manure scraping, type of manure scraping, stock density, comfort of bedding area, grazing management, and consistency of feces. The relative effect of each factor may be difficult to identify, but it could be interesting to establish which combinations would provide a sufficiently hygienic environment for feet. In such studies, even if leg and foot cleanliness were linked, we would advise measuring foot cleanliness rather than leg cleanliness to take into account the real environment of the foot at each measure.

In the present study, we did not find any effect of several factors that had previously been identified as risk factors for DD, including type of housing, grazing, proportion of calving heifers (calving season), parity, and lactation stage (Laven, 1999; Rodriguez-Lainz et al., 1999; Somers et al., 2005). However, cows in third parity or higher and cows on pasture were significantly associated with faster cure of DD in univariate analysis. These factors may not have been associated with faster cure in multivariate analysis because of a lack of statistical power, notably because most of the cows were housed when they experienced DD and healing occurred quickly, before cows had access to pasture. Moreover, some risk factors may have a greater effect on DD prevention than on DD cure.

One limitation of this trial was the potential existence of a selection bias due to the unwillingness of some farmers to participate in any of the treatment regimens. We can assume that the farmers who agreed to participate when collective treatments had to be 
applied every 2 weeks were more conscientious than those who agreed to participate only if treatments were applied every 4 wk. In addition, some unchecked factors may have been different between farms, such as strains of Treponema with different pathogenicities (Edwards et al., 2003; Elliott et al., 2007), different susceptibilities of Treponema to treatments (Evans et al., 2009), or different levels of immunity of the cows (Read and Walker, 1998; Elliott and Alt, 2009). It would be interesting to investigate the effect of these factors on the cure of DD and to account for them in future studies assessing the effectiveness of control measures against DD.

\section{CONCLUSIONS}

The results of this field trial indicate that several measures should be combined to ensure the rapid recovery of digital dermatitis in endemically affected dairy herds. Collective topical treatments using a copper and zinc chelates solution can be useful to quicken healing of DD lesions as they also cure undetected lesions, particularly small ones that are more difficult to detect but that heal best. To be more effective than the individual spraying of oxytetracycline alone, such collective treatments must be applied to cleaned feet at least every 2 wk, either through collective spraying in the milking parlor or by a walk-through split footbath. The management factor that greatly affected the healing of DD lesions was leg cleanliness. Further research is needed to understand which combination of management practices could provide a sufficiently hygienic environment for feet.

\section{ACKNOWLEDGMENTS}

We greatly acknowledge all the participants of this study: the farmers for their hospitality, technicians of animal health service (Brittany and Pays-de-la-Loire, France), and the veterinarians involved as investigators for their time and motivation. We thank Jean-Yves Audiart, Juliette Bordot, Marleen Bruggink, Anne Chesnin, and Damien Deiss (INRA-Oniris, Nantes, France) for their help regarding entering of data. We also thank Vincent Ducrocq (INRA, Jouy-en-Josas, France) for his help regarding use of the Survival Kit. Thanks are due to the technical committee of the "Mortellaro project" (UMT Cattle Health Management, Nantes, France) for advice. The authors gratefully acknowledge Intracare, Dominique Bernier (SARL Bov'idée, St Sauveur des Landes, France), and MSD Animal Health/Intervet (Beaucouzé, France) for providing all hoof-care products, footbaths, and sprayers.

\section{REFERENCES}

Akaike, H. 1974. A new look at the statistical model identification. IEEE Trans. Autom. Contr. 19:716-723.

Auzanneau, M. M. 2009. Page 171 in Etat des Lieux des Pratiques de Gestion de la Maladie de Mortellaro par les Éleveurs de Bovins [Inventory Practices of French Dairy Farmers to Control Digital Dermatitis (Mortellaro Disease)]. Oniris, Nantes, France.

Berry, S. L., R. L. Walker, D. H. Read, D. W. Hird, and R. A. Ertze. 2004. The current state of knowledge on (papillomatous) digital dermatitis in dairy cattle: With particular reference to control. Pages 130-137 in Proc. 13th Int. Symp. 5th Conf. Lameness Ruminants. B. Zemljič, ed. B. Zemljič, Maribor, Slovenia.

Bruijnis, M. R. N., H. Hogeveen, and E. N. Stassen. 2010. Assessing economic consequences of foot disorders in dairy cattle using a dynamic stochastic simulation model. J. Dairy Sci. 93:2419-2432.

Cook, N. 2006. Footbath alternatives (Jul. 14, 2011). Accessed Dec. 3, 2011. http://www.karlburgi.com/common/pdfs-articles/Footbath\%20Alternatives.pdf.

Cox, D. D., and E. J. Snell. 1966. A general definition of residuals. J. R. Stat. Soc. B 30:248-275.

Cox, D. R. 1972. Regression models and life tables. J. R. Stat. Soc. B $34: 187-220$.

Dohoo, I., W. Martin, and H. Stryhn. 2003. Veterinary Epidemiologic Research. 1st ed. University of Prince Edward Island, Charlottetown, PEI, Canada.

Döpfer, D. 2009. Digital Dermatitis. The dynamics of digital dermatitis in dairy cattle and the manageable state of disease. CanWest Veterinary Conference. Accessed Dec. 3, 2011. http://www.hoofhealth.ca/Dopfer.pdf.

Döpfer, D., A. Koopmans, F. A. Meijer, I. Szakall, Y. H. Schukken, W. Klee, R. B. Bosma, J. L. Cornelisse, A. J. van Asten, and A. A. ter Huurne. 1997. Histological and bacteriological evaluation of digital dermatitis in cattle, with special reference to spirochaetes and Campylobacter faecalis. Vet. Rec. 140:620-623.

Ducrocq, V., J. Sölkner, and G. Meszaros. 2010. Survival Kit v6-A software package for survival analysis. Proc. 9th World Congr. Genet. Appl. Livest. Prod., Leipzig, Germany. German Society for Animal Science, Leipzig, Germany.

Edwards, A. M., D. Dymock, and H. F. Jenkinson. 2003. From tooth to hoof: Treponemes in tissue-destructive diseases. J. Appl. Microbiol. 94:767-780.

Elliott, M. K., and D. P. Alt. 2009. Bovine immune response to papillomatous digital dermatitis (PDD)-associated spirochetes is skewed in isolate reactivity and subclass elicitation. Vet. Immunol. Immunopathol. 130:256-261.

Elliott, M. K., D. P. Alt, and R. L. Zuerner. 2007. Lesion formation and antibody response induced by papillomatous digital dermatitis-associated spirochetes in a murine abscess model. Infect. Immun. 75:4400-4408.

Evans, N. J., J. M. Brown, I. Demirkan, R. Birtles, C. A. Hart, and S. D. Carter. 2009. In vitro susceptibility of bovine digital dermatitis associated spirochaetes to antimicrobial agents. Vet. Microbiol. 136:115-120.

Fiedler, A. 2004. Investigation of the efficacy of the Kovex-foam-system in the decrease of the incidence of dermatitis digitalis, dermatitis interdigitalis and Erosio ungulae. Pages 148-150 in Proc. 13th Int. Symp. 5th Conf. Lameness Ruminants. B. Zemljič, ed. B. Zemljič, Maribor, Slovenia.

Green, L. E., J. Borkert, G. Monti, and N. Tadich. 2010. Associations between lesion-specific lameness and the milk yield of 1,635 dairy cows from seven herds in the Xth region of Chile and implications for management of lame dairy cows worldwide. Anim. Welf. 19:419-427.

Guterbock, W. M., C. L. Borelli, and D. H. Read. 1995. Evaluation of four therapies of papillomatous digital dermatitis in dairy cattle. Pages 240-241 in Proc. Annu. Mtg. Am. Assoc. Bovine Pract. (AABP). AABP, Auburn, AL.

Holzhauer, M., C. J. Bartels, D. Döpfer, and G. van Schaik. 2008. Clinical course of digital dermatitis lesions in an endemically infected herd without preventive herd strategies. Vet. J. 177:222-230. 
Holzhauer, M., C. Hardenberg, C. J. Bartels, and K. Frankena. 2006. Herd- and cow-level prevalence of digital dermatitis in the Netherlands and associated risk factors. J. Dairy Sci. 89:580-588.

IARC. 2004. IARC classifies formaldehyde as carcinogenic to humans IARC Press Release. (153). Accessed Dec. 3, 2011. http://www. iarc.fr/en/media-centre/pr/2004/pr153.html.

Journel, C., and T. Carteron. 2001. Effet de la mise en place du procédé d'hygiène P3-Kovex Foam sur l'évolution des lésions de dermatite digitée des vaches laitières dans deux élevages. Pages 168-169 in Renc. Rech. Ruminants, Paris, France. INRA-Institut de l'Elevage, Paris, France.

Kalbfleisch, J. D., and R. L. Prentice. 2002. The Survival Analysis of Failure Time Data. 2nd ed. Wiley Series in Probability and Statistics. John Wiley \& Sons, Hoboken, NJ.

Kofler, J., M. Pospichal, and M. Hofmann-Parisot. 2004. Efficacy of the non-antibiotic paste Protexin Hoof-Care for topical treatment of digital dermatitis in dairy cows. J. Vet. Med. A Physiol. Pathol. Clin. Med. 51:447-452.

Laven, R. 2003. Desktop review into the management and treatment of digital dermatitis. Technical Report No. 02/T3/07. Milk Development Council, Cirencester, UK.

Laven, R. A. 1999. The environment and digital dermatitis. Cattle Pract. 7:349-355.

Laven, R. A., and H. Hunt. 2002a. The efficacy of non-antibiotic footbaths in the control of digital dermatitis in the UK. Pages 366-368 in Proc. 12th Int. Symp. Lameness Ruminants, Orlando, FL. J. K., Shearer, ed.

Laven, R. A., and H. Hunt. 2002b. Evaluation of copper sulphate, formalin and peracetic acid in footbaths for the treatment of digital dermatitis in cattle. Vet. Rec. 151:144-146.

Laven, R. A., and D. N. Logue. 2006. Treatment strategies for digital dermatitis for the UK. Vet. J. 171:79-88.

Laven, R. A., and M. J. Proven. 2000. Use of an antibiotic footbath in the treatment of bovine digital dermatitis. Vet. Rec. 147:503-506.

Logue, D. 2011. Understanding bovine digital dermatitis. Vet. Rec. $168: 212-213$.

Losinger, W. C. 2006. Economic impacts of reduced milk production associated with papillomatous digital dermatitis in dairy cows in the USA. J. Dairy Res. 73:244-256.

Manske, T., J. Hultgren, and C. Bergsten. 2002. Topical treatment of digital dermatitis associated with severe heel-horn erosion in a Swedish dairy herd. Prev. Vet. Med. 53:215-231.

Moher, D., S. Hopewell, K. F. Schulz, V. Montori, P. C. Gotzsche, P. J. Devereaux, D. Elbourne, M. Egger, and D. G. Altman. 2010. CONSORT 2010 explanation and elaboration: Updated guidelines for reporting parallel group randomised trials. BMJ 340:c869.

Nielsen, B. H., P. T. Thomsen, and J. T. Sørensen. 2011. Identifying risk factors for poor hind limb cleanliness in Danish loose-housed dairy cows. Animal 5:1613-1619.

Nishikawa, A., and K. Taguchi. 2008. Healing of digital dermatitis after a single treatment with topical oxytetracycline in 89 dairy cows. Vet. Rec. 163:574-576.

O'Connor, A. M., J. M. Sargeant, I. A. Gardner, J. S. Dickson, M. E. Torrence, C. E. Dewey, I. R. Dohoo, R. B. Evans, J. T. Gray, M. Greiner, G. Keefe, S. L. Lefebvre, P. S. Morley, A. Ramirez, W. Sischo, D. R. Smith, K. Snedeker, J. Sofos, M. P. Ward, and R. Wills. 2010. The REFLECT statement: Methods and processes of creating reporting guidelines for randomized controlled trials for livestock and food safety. Prev. Vet. Med. 93:11-18.

Plomp, G. H. M. 2002. Practical trial: Intra-bath concept. Page 12. HX-UTD Nutreco/Intracare BV Haaften, Haaften, the Netherlands.

Read, D. H., and R. L. Walker. 1998. Papillomatous digital dermatitis (footwarts) in California dairy cattle: Clinical and gross pathologic findings. J. Vet. Diagn. Invest. 10:67-76.

Relun, A., R. Guatteo, N. Bareille, and P. Roussel. 2011. A simple method to score digital dermatitis in dairy cows in the milking parlor. J. Dairy Sci. 94:5424-5434

Rodriguez-Lainz, A., D. W. Hird, and D. H. Read. 1996. Case-control study of papillomatous digital dermatitis in southern California dairy farms. Prev. Vet. Med. 28:117-131.

Rodriguez-Lainz, A., P. Melendez Retamal, D. W. Hird, D. H. Read, and R. L. Walker. 1999. Farm- and host-level risk factors for papillomatous digital dermatitis in Chilean dairy cattle. Prev. Vet. Med. 42:87-97.

Schreiner, D. A., and P. L. Ruegg. 2002. Effects of tail docking on milk quality and cow cleanliness. J. Dairy Sci. 85:2503-2511.

Shearer, J. K., and J. Hernandez. 2000. Efficacy of two modified nonantibiotic formulations (Victory) for treatment of papillomatous digital dermatitis in dairy cows. J. Dairy Sci. 83:741-745.

Somers, J. G., K. Frankena, E. N. Noordhuizen-Stassen, and J. H. Metz. 2003. Prevalence of claw disorders in Dutch dairy cows exposed to several floor systems. J. Dairy Sci. 86:2082-2093.

Somers, J. G., K. Frankena, E. N. Noordhuizen-Stassen, and J. H. Metz. 2005. Risk factors for digital dermatitis in dairy cows kept in cubicle houses in The Netherlands. Prev. Vet. Med. 71:11-21.

Speijers, M. H. M., L. G. Baird, G. A. Finney, J. McBride, D. J. Kilpatrick, D. N. Logue, and N. E. O'Connell. 2010. Effectiveness of different footbath solutions in the treatment of digital dermatitis in dairy cows. J. Dairy Sci. 93:5782-5791.

Stehouwer, R., and G. Roth. 2004. Copper sulfate hoof baths and copper toxicity in soil. Penn State University Field Crop News. 4. Accessed Dec. 3, 2011. www.das.psu.edu/news/dd200403-03.

Teixeira, A. G. V., V. S. Machado, L. S. Caixeta, R. V. Pereira, and R. C. Bicalho. 2010. Efficacy of formalin, copper sulfate, and a commercial footbath product in the control of digital dermatitis. J. Dairy Sci. 93:3628-3634.

Thomsen, P. T., J. T. Sorensen, and A. K. Ersboll. 2008a. Evaluation of three commercial hoof care products used in footbaths in Danish dairy herds. Pages 178-179 in Proc. 15th Int. Symp. 7th Conf. Lameness Ruminants, Kuopio, Finland. J. Niemi, ed.

Thomsen, P. T. J. T. Sørensen, and A. K. Ersbøll. 2008b. Evaluation of three commercial hoof-care products used in footbaths in Danish dairy herds. J. Dairy Sci. 91:1361-1365.

Vink, W. D. 2006. Perspectives for BDD: Current knowledge and research priorities. Page 267 in Investigating the Epidemiology of Bovine Digital Dermatitis: Causality, Transmission and Infection Dynamics. University of Liverpool, Liverpool, UK.

Wells, S. J., L. P. Garber, and B. A. Wagner. 1999. Papillomatous digital dermatitis and associated risk factors in US dairy herds. Prev. Vet. Med. 38:11-24.

Yeruham, I., and S. Perl. 1998. Clinical aspects of an outbreak of papillomatous digital dermatitis in a dairy cattle herd. J. S. Afr. Vet. Assoc. 69:112-115. 